\title{
Assessment of waste management practices in hospitals of Islamabad and Abbottabad-Pakistan
}

Khushbukhat Khan*, Sidra Shaheen, Huma Iqbal, Ghazala Mushtaq Raja, RohinaArif, Madeeha Khalil, Amna Munawaar, Maryem Batool, Maryiam Farooq, Hafsa Khan, Areej Abdul Sattar, Khadija Ilyas, Azka Tariq, Sehrish Khan, Ayesha Hanna and Tayyaba Ehsaan

Department of Bioinformatics and Biotechnology, International Islamic University, Sector H-10, Islamabad-44000, Pakistan

*Corresponding author's email: khushi-khan2011@hotmail.com

\section{Citation}

Khushbukhat Khan, Sidra Shaheen, Huma Iqbal, Ghazala Mushtaq Raja, RohinaArif, Madeeha Khalil, AmnaMunawaar, MaryemBatool, Maryiam Farooq, Hafsa Khan, Areej Abdul Sattar, Khadija Ilyas, Azka Tariq, Sehrish Khan, Ayesha Hanna and TayyabaEhsaan. Assessment of waste management practices in hospitals of Islamabad and Abbottabad-Pakistan. Pure and Applied Biology. Vol. 9, Issue 1, pp282-289. http://dx.doi.org/10.19045/bspab.2020.90033

\begin{tabular}{llll}
\hline \hline Received: 26/07/2019 & Revised: 19/09/2019 & Accepted: 11/10/2019 & Online First: 23/10/2019 \\
\hline
\end{tabular}

\section{Abstract}

Hospital's wastes (HW) are considered the most hazardous category of waste. According to World Health Organization (WHO), HW is a special waste whose disposal required special procedure and care. The conditions regarding hospital waste management (HWM) in developing countries are discordant with prescribed management methods. Unfortunately, Pakistan is also among countries where not much attention is paid to waste management (WM). To device any combating strategy, there is a need of proper data describing: the conditions of the country's hospitals, methods used for waste management and factors hindering the disposal process. So, current study is conducted to assess the present conditions of waste management in two cities of Pakistan Islamabad and Abottabad. Major factors which influence the safe disposal of hospital waste are also highlighted. The results obtained indicate the unawareness and ill practices in hands of waste handling staff, thus suggesting proper training of medical staff such as sanitary workers and an observant administrative system to reduce poor hygienic conditions. Proper waste handling and WM practices in hospitals will not only keep physicians, waste handling staff and patients from harm's way but will also reduce probability of environmental contamination.

Keywords: Hospital waste management; Hospital waste; Infectious waste; Pakistan hospitals; waste management

\section{Introduction}

Health care centers are an essential component of a society. Varity of waste is generated from hospitals or health care centers due to the employment of medicines, food, chemicals and different instruments etc for the treatment of patients. This waste can be classified into two main categories: 1) Medical/Clinical waste comprising of infectious waste, pathological waste, sharps, 
pharmaceutical waste, blood, swaps, genotoxic waste, chemical waste and radioactive waste 2) Non-medical or non-clinical waste including foodstuff leftovers, cardboards, packages, etc [1]. Such diverse infectious and hazardous wastes could cause high risk of health concerns on direct contact and can indirectly cause contamination of environment [2].

To tackle it, hospitals established waste management regulations and different hospitals use different methods and technologies to treat hospital waste. It is stated in WHO report (2002), around 64\% hospitals in 22 countries in world have improper methods for disposing waste [3]. Some studies have even revealed that hospital waste management is not up to the Environmental Protection Agency (EPA) standards in developing countries [4] and Pakistan is one such developing country. According to one study in Nepal, these low standards are due to the lack of waste management planning and carelessness of doctors, nurses and visitors [5].

Studies from Pakistan reported that majority of hospitals and independently working physicians do not practice proper methods of waste handling and disposal [6] which results in the direct and frequent contact of doctors, patients, visitors and other people around to hazardous hospital wastes [2,7].

So, for this reason present study was conducted in private and public hospitals of Islamabad and Abbotabad. The main objectives of this study are to review the currently practiced waste management methods in Islamabad and Abbottabad's private and government hospitals and to identify the factors which influences the proper waste disposal.

\section{Materials and methods}

This was a qualitative type of research in which we used designed survey forms and questionnaires and interviewed concerning authorities. Through questionnaires and interviews, the emphasize $\mathrm{w}$ as put on queries about the educational qualification of the persons handling toxic, non - toxic and sanitary waste, the quantity of waste, the methods used for its segregation and disposal, legislation from health ministry regarding HWM and the total amount of money required for the proper disposal of this waste.

Total 14 hospitals were selected from Islamabad and Abbotabad for the survey. Out of which 6 were private and 8 were public hospitals (Table 1). The personnel administrating the waste management departments of each hospital were contacted to get the authentic information.

\section{Results and discussion}

The results are based on questionnaire survey with the officials concerned with waste management and observation of the study sites by the authors. Almost all surveyed hospitals from public and private sector in Islamabad and Abbotabad had WM teams but the practices of WM teams working in private hospitals of Abbotabad were deviant from standard methods.

WM team should generally comprise of seventeen members including head of WM department, liaison officer, sanitary inspector, head of domestic staff and rest should be part of domestic staff. In Islamabad, one private while in Abbotabad one public hospital did not have WM team at all. Rest of the hospitals had functional WM teams. Main factor which we found greatly influential in the waste management is education. General education of domestic staff who directly handled waste was: matriculation or below in both cities (Figure 1). The heads of domestic staff were intermediate with one diplomatin "ward management" whose duties comprised of: keeping check on domestic staff and reporting to liaison officer. Liaison officers were graduates while sanitary inspectors were graduates with diploma in sanitary 
inspector course. Education of heads of WM department was graduation and some MBBS doctors were also recruited at this post.

In majority of surveyed hospitals in both cities, we observed that instructions were given to staff for handling waste. Further, the clear procedures for waste collection and handling were also available. But among all surveyed public hospitals of Abbotabad, two government hospitals did not delivered proper instructions regarding waste management to staff. Similarly, in surveyed government hospitals of Islamabad, only one hospital did not delivered WM instructions to domestic staff despite having proper methods and protocols for handling waste. Further, it is observed that, in some hospitals of both cities, instructions and training were delivered but strict implementation of protocols was not happening. The reason behind it can be the lack of awareness to the hazards of such practices or the mere carelessness of doctors or authorities [5] Further, it is found that no proper workshops or campaigns were ever conducted to make general public and hospital workers aware of the hazards which hospital waste mismanagement can cause. Possible reason would be the unconcern of people of workers toward consequences of rough handling of HW. A case study in Nigeria by Ezeoke Uchechukwu et al. [8] revealed that most of the healthcare workers were aware of the risks associated with the careless attitude handling of HW. Still due to negligible check by authorities and no awareness campaigns, those workers tend to show incautious behaviors.

A legislation in the form of document name "Hospital Waste Management Rules, 2005" from government on Hospital waste management is available which clearly states that it is the duty and responsibility of hospital authorities and staff working under them to properly dispose HW in such a way that it cause no more threat to environment and beings living in that environment (Environment Protection Act 1997). After interviewing authorities and domestic staff, we found that in Islamabad, heads of WM team were well aware of this legislation but domestic staff had no clue of its existence. Contrarily private hospitals of Abbotabad were thoroughly unaware of this legislation and some even denied that any legislation from government is even available. Finding of this study are in accord with the findings of Ali et al.[9] who also reported that WM team in most private hospitals of Gujranwala City had no knowledge of Waste Management Legislation. Few of the hospitals in both cities even had their own manuals for hospital waste handling and degradation where the viability of these manuals is uncertain. The graphical representations of WM teams in both cities who were aware of legislations provided by government are shown in figure 2 .

Segregation of waste is the first step for waste disposal. Most hospitals around the world uses labeled dustbins either with tags or colours for waste segregation [2]. This segregation in both cities in some hospitals is done at the spot where dustbins were labeled with different colors or tags, specifying the waste bin for specific category of waste and are disposed off accordingly (Table 2). But this segregation in most hospitals of Abbotabad was done in separate rooms after collecting waste of whole hospital. While in Islamabad, segregation in one hospital was done before its final disposal.

Labeling of dustbins is important for proper waste segregation. Except of one pubic hospital in Islamabad, almost all hospitals had proper labeling system. While in Abbotabad, it is observed that many government and private hospitals did not have proper labeling system. It also came into our observation that in spite of all labeling the wastes were not thrown in its specific buckets which clearly indicates the careless behavior 
of doctors and nurses. Some nurses there even complained that doctors actually do not follow the labeling patterns. They throw all types of waste in one bucket which later causes issues during waste segregation. Most workers who did not pay much attention to throw waste in specific dust bins were usually unaware of the importance of waste segregation [2]. Contrarily, in current case doctors and nurses had complete awareness of its significance, yet only out of laziness and no fear of accountability they chose not to cooperate.

For safe transport, storage or segregation of waste, material in which it is collected is of real importance. All hospitals chosen for this study used plastic bags or boxes, cardboard boxes and metal containers for waste collection. The general trends of material used for waste management in government hospitals of both cities are shown in figure 3 . According to our observation, in Abbottabad, majority workers in government hospitals did not use gloves, masks or special clothing for handling waste, although these materials were provided to them by the authorities. In Islamabad, private hospitals' domestic staff was not taking protective measures for handling waste and domestic staff of government hospital was taking all possible measures while dealing with waste. Use of proper safety while handling waste is reported in Nigerian hospital [8].

As discussed earlier, different categories of wastes are produced in hospitals [1] due to diverse range of activities. Similarly different techniques are used to dispose them. Three major techniques are employed in these two cities. 1) Incineration 2) Landfill 3) Burned openly. All these methods have their associated risks [10] but if employed properly then are beneficial in treating HW [11]. In Islamabad, sharps were generally incinerated but one hospital even used municipal landfills to dispose it. While in Abbotabad, government hospitals incinerated it but private hospitals preferred burning of waste on hospital grounds or burying it on municipal landfills. Similarly, in Abbotabad, pathological waste was disposed of using all three mentioned techniques but in Islamabad incineration was preferred. For radioactive wastes, both cities hospitals took special measures. First, they neutralized its effects and then, they incinerated it or dumped it on landfills. Sanitary wastes were disposed of in landfills in Islamabad but in Abbotabad, some government hospitals burned it on hospital grounds. All three techniques were used to dispose pharmaceutical waste in both cities. A case study in Nanjing, China reported the use of incineration system for disposing of the HWs [12]. While majority hospitals in Nigeria burn $\mathrm{HW}$ in pits or incinerate it [8]. Landfilling is preferred method reported in Bauru, Brazile [13]. The most practiced method for waste disposal in both cities is shown in figure 4 .

The chief factor which directly affects the $\mathrm{WM}$ in hospitals is funding. In Islamabad, according to information gathered from hospital authorities, only one government hospital received government funds and it is observed that waste management team in that hospital took all possible measures to dispose HW according to methods declared by WHO. Similarly, in Abbotabad, only one government hospital received government funds for waste management and authorities there also followed standard methods for WM.

Table 1. List of number of private and public hospitals chosen for study

\begin{tabular}{|c|c|c|}
\hline City & Private & Public \\
\hline Islamabad & 2 & 5 \\
\hline Abbotabad & 4 & 3 \\
\hline
\end{tabular}


Table 2. Labels used to indicate specific type of waste

\begin{tabular}{|c|c|}
\hline Label & Type of waste \\
\hline Red & Infectious \\
\hline Yellow/gray & Non-infectious(drips, gowns etc) \\
\hline Blue & Garbage and rappers \\
\hline
\end{tabular}

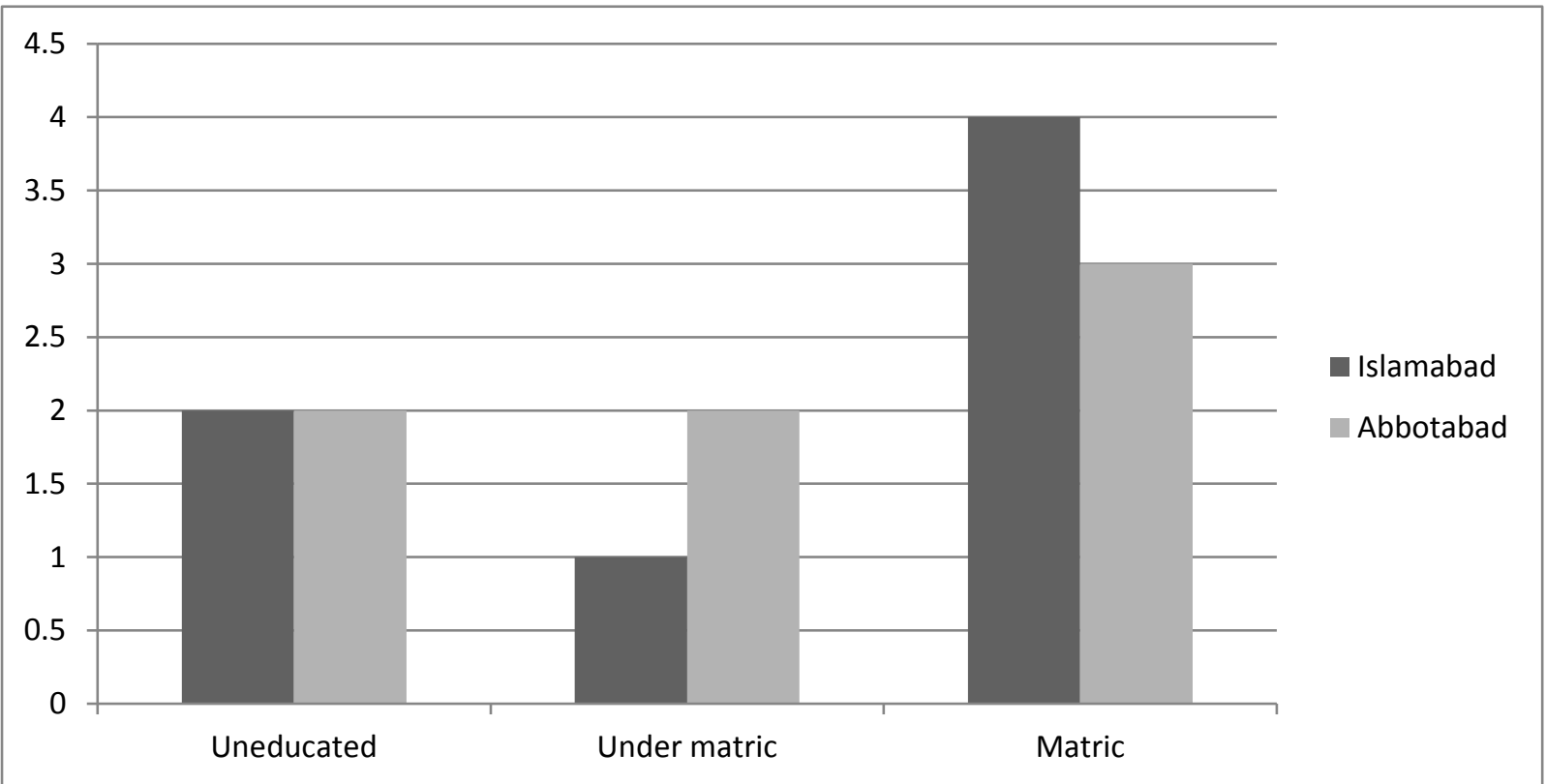

Figure 1. Graphical representation of general education of domestic staff of Waste management team in Islamabad and Abbotabad

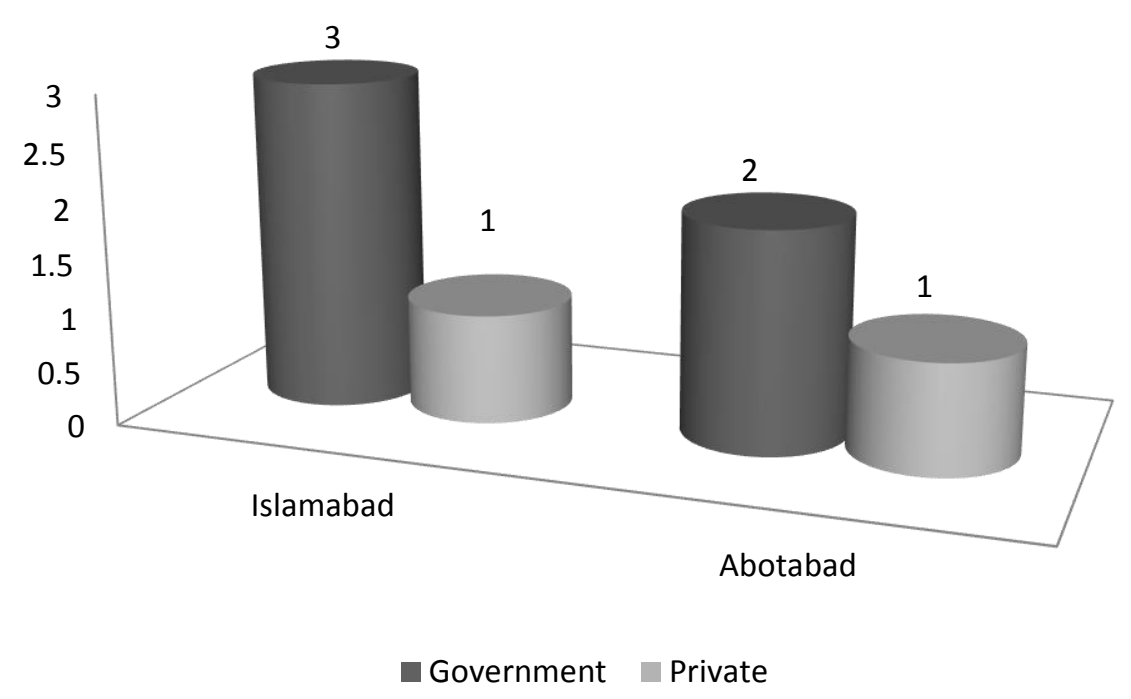

Figure 2. Graphical representation of number of hospitals whose WM staff is aware of legislation provided by Ministry of Health regarding waste management 
Khan et al.

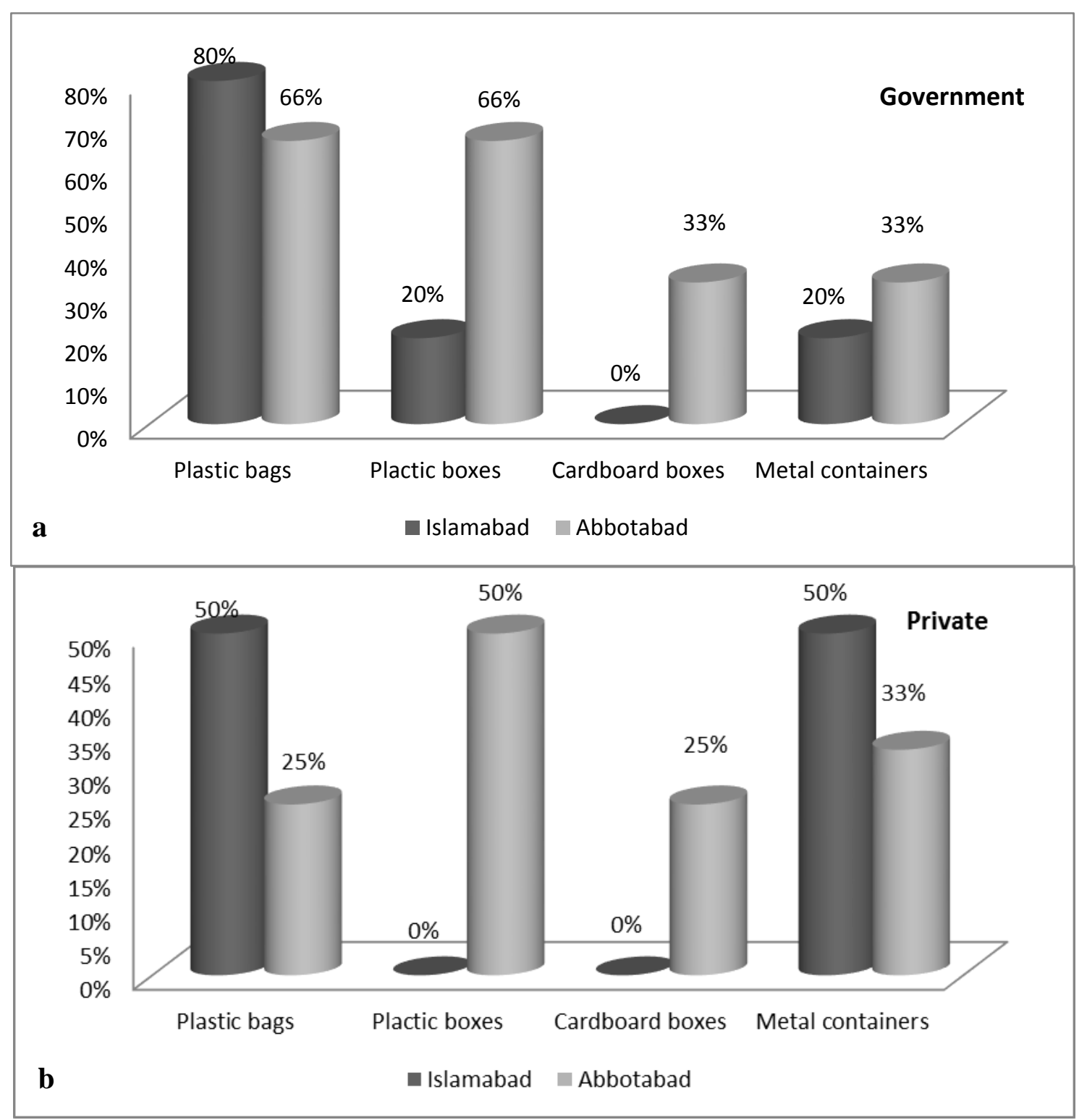

Figure 3. Illustration showing preference for material in Islamabad and Abbotabad's hospitals for waste segregation, storage and transport a) government hospitals b) private hospitals 


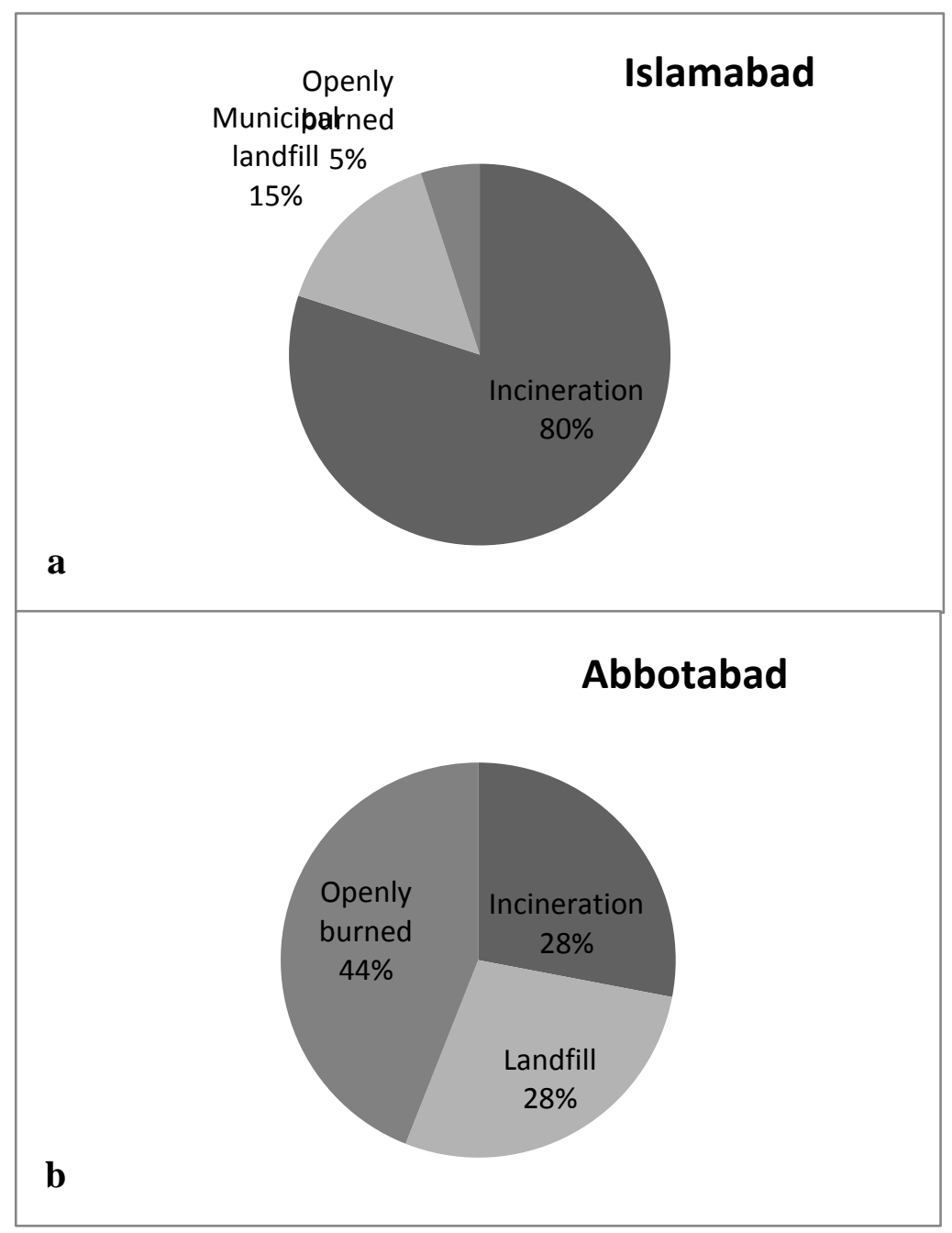

Figure 4. Pie chart representation of general trends of disposal techniques chosen by the hospitals in Islamabad (a) and Abbotabad (b)

\section{Conclusion and recommendation}

The analysis of information obtained brought to limelight numerous facts which affects proper waste disposal in Islamabad and Abbottabad hospitals. To ensure proper HW disposal and to minimize the risks associated with improper disposal of hospital waste, following measures must be taken:

- Before recruiting any person for WM, his/her proper training should be done.

- The implementation of laws should be confirmed by the higher authorities.

- Campaigns or brochures should be provided in hospitals, first to make them aware to EPA rule 2007 and second, for reminder to follow these rules.

- Teams from government should be sent to hospitals periodically to ensure proper waste handling and disposal.

- Funds from government should be provided to all types of hospitals.

Mismanagement in hospital waste disposal is a serious threat to environment. The main issue in waste handling arises due to carelessness of doctors and nurses. Moreover, due to absence of proper awareness, domestic staff exposes themselves and also others to hazardous HW. Lack of funding by government is another 
very vital factor which creates hitches in proper disposal of waste. The information gathered in present study is totally based on survey and interview, so, there are huge chances of subjective errors. Further studies are required in hospitals of this area to find out other factors which cause the improper waste disposal and to find the possible health and environmental damages which might occur when hospital waste is not disposed off appropriately.

\section{Authors' contributions}

Conceived and designed the study: $\mathrm{M}$ Farooq, A Hanna \& H Iqbal, Data collection: S Shahenn, GM Raja, R Arif, M Khalil, MBatool, MFarooq, H Khan, K Iqbal, A Tariq, S Khan, $\mathrm{T}$ Ehsaan \& A Hanna, Analysis of the data: K Khan, S Khan \& H Khan, Paper was written: K Khan, AA Sattar, A Munawar, H Iqbal \& H Khan.

\section{Acknowledgement}

All authors are grateful to Dr Sobia Tabassum from Department of Bioinformatics and Biotechnology, International Islamic University, Islamabad, Pakistan for encouraging this research. There has been no significant financial support for this work that could have influenced its outcome.

\section{References}

1. Hashmi SK \& Shahab S (2003) Community medicine and public health. Time Publishers. Karachi, Pakistan. pp 426-437.

2. Maina JW (2018). Knowledge, Attitude and Practice of Staff on Segregation of Hospital Waste: A Case Study of a Tertiary Private Hospital in Kenya. Eur. Sci. J 14: 401-417

3. Singh RP, Singh P, Araujo ASF, Hakimi Ibrahim M \&Sulaiman O (2011). Management of urban solid waste: Vermicomposting a sustainable option. Resour, Conserv and Recycl55: 719-729.

4. World Health Organization. Health-care waste management. (2011): Available from:
Paudel R \& Pradhan B (2010). Health care waste management practice in a hospital. $J$ Nepal Health Res Counc8:86-90.

5. Ikram A, Hussain Shah SI, Naseem S, Absar SF, Ullah S, Ambreen T, Sabeeh SM \&Niazi SK (2010). Status of hospital infection control measures at seven major tertiary care hospitals of northern Punjab. $J$ Coll Physicians Surg Pak 20: 266-70.

6. Janjua NZ (2003). Injection practices and sharp waste disposal by general practitioners of Murree, Pakistan. J Pak Med Assoc53: 107-11.

7. Ezeoke Uchechukwu E, Omotowo Babatunde I \& Ndu Anne C (2017). Investigating Knowledge, Attitude and Health Care Waste Management by Health Workers in a Nigerian Tertiary Health Institution. Glob J Health Sci 9: 222-223.

8. Ali M, Wang W, Chaudhary N, Geng Y \& Ashraf U (2017). Assessing knowledge, performance, and efficiency for hospital waste management - a comparison of government and private hospitals in Pakistan. Environ Monit and Assess 189: 181-190.

9. Hoenich NA \& Pearce C (2002). Medical waste production and disposal arising from renal replacement therapy. Adv Ren Replace Ther9: 57-62.

10. Orloff K \& Falk H (2003). An international perspective on hazardous waste practices. Int J Hyg Environ Health 206: 291-302.

11. Yong Z, Gang X, Guanxing W, Tao Z \&Dawei J (2009). Medical waste management in China: A case study of Nanjing. Waste Manag29: 1376-1382.

12. Delmonico D, Santos H, Pinheiro M, Castro R \& Souza R (2018). Waste management barriers in developing country hospitals: Case study and AHP analysis Waste Manag Res 35: 48-58.

13. Delmonico D, Santos H, Pinheiro M, Castro R \& Souza R (2018). Waste management barriers in developing country hospitals: Case study and AHP analysis. Waste Manag Res 35: 48-58. 